\title{
Gender-specific estimates of COPD prevalence: a systematic review and meta-analysis
}

This article was published in the following Dove Press journal: International journal of COPD

\author{
Georgios Ntritsos' \\ Jacob Franek ${ }^{2}$ \\ Lazaros Belbasis' \\ Maria A Christou' \\ Georgios Markozannes' \\ Pablo Altman ${ }^{3}$ \\ Robert Fogel ${ }^{3}$ \\ Tobias Sayre ${ }^{2}$ \\ Evangelia E Ntzani' \\ Evangelos Evangelou ${ }^{1,4}$ \\ 'Clinical and Molecular Epidemiology \\ Unit, Department of Hygiene and \\ Epidemiology, School of Medicine, \\ University of loannina, loannina, \\ Greece; ' Doctor Evidence, Client \\ Solutions, Santa Monica, CA, USA; \\ ${ }^{3}$ Global Medical Affairs, Novartis \\ Pharmaceuticals Corporation, \\ East Hanover, NJ, USA; ${ }^{4}$ Department \\ of Epidemiology and Biostatistics, \\ Imperial College London, London, UK
}

Correspondence: Evangelos Evangelou Clinical and Molecular Epidemiology Unit, Department of Hygiene and Epidemiology, School of Medicine, University of loannina, University Campus, loannina 45I I0, Greece Email vangelis@cc.uoi.gr
Rationale: COPD has been perceived as being a disease of older men. However, $>7$ million women are estimated to live with COPD in the USA alone. Despite a growing body of literature suggesting an increasing burden of COPD in women, the evidence is limited.

Objectives: To assess and synthesize the available evidence among population-based epidemiologic studies and calculate the global prevalence of COPD in men and women.

Materials and methods: A systematic review and meta-analysis reporting gender-specific prevalence of COPD was undertaken. Gender-specific prevalence estimates were abstracted from relevant studies. Associated patient characteristics as well as custom variables pertaining to the diagnostic method and other important epidemiologic covariates were also collected. A Bayesian randomeffects meta-analysis was performed investigating gender-specific prevalence of COPD stratified by age, geography, calendar time, study setting, diagnostic method, and disease severity.

Measurements and main results: Among 194 eligible studies, summary prevalence was $9.23 \%$ (95\% credible interval [CrI]: $8.16 \%-10.36 \%$ ) in men and $6.16 \%(95 \% \mathrm{CrI}$ : $5.41 \%-6.95 \%$ ) in women. Gender prevalences varied widely by the World Health Organization Global Burden of Disease subregions, with the highest female prevalence found in North America (8.07\% vs $7.30 \%$ ) and in participants in urban settings (13.03\% vs $8.34 \%$ ). Meta-regression indicated that age $\geq 40$ and bronchodilator testing contributed most significantly to heterogeneity of prevalence estimates across studies.

Conclusion: We conducted the largest ever systematic review and meta-analysis of global prevalence of COPD and the first large gender-specific review. These results will increase awareness of COPD as a critical woman's health issue.

Keywords: COPD, prevalence, meta-analysis, gender, age, systematic review

\section{Introduction}

COPD is a condition in which the lung airways become inflamed and narrowed and the air sacs become damaged. It is a major cause of morbidity and mortality around the globe. ${ }^{1-3}$ It has been estimated that by 2030 , COPD will be one of the top causes of death worldwide. ${ }^{4-6}$ While tobacco smoke is the most common cause of COPD, ${ }^{7}$ it is estimated that $20 \%$ of people who develop COPD have never smoked. ${ }^{8}$ Other putative risk factors include an abnormal sensitivity and exaggerated response to inhaled substances and other exposures such as second-hand smoking, use of biomass fuels, exposure to environmental dust or organic material in the workplace, or exposure to air pollution. ${ }^{9}$ COPD is diagnosed through spirometry, which can detect COPD even in people who do not yet have symptoms. Currently, there is no cure for COPD, although available therapy can improve symptoms, quality of life, and prevent acute worsening of the disease. ${ }^{10}$

Once thought of primarily as a disease of older male smokers, COPD has become increasingly prevalent among women. Recent evidence suggests that the prevalence and 
mortality of COPD have increased more rapidly in women than in men. ${ }^{11,12}$ Although increasing tobacco consumption among women during the past several decades is linked to the rising prevalence of COPD in women, the relationship may be more complex, including additional factors such as differential susceptibility to tobacco, greater exposure to indoor air pollution, anatomic and hormonal differences, as well as behavioral differences in response to available therapeutic modalities. However, the extent of the differences in prevalence of COPD between men and women is not well understood and may vary by geography or other factors. ${ }^{13}$ Unfortunately, populationbased estimates of COPD prevalence by region are problematic since the disease is progressive, measurement tools and definitions vary among studies, and implementation of spirometry is often not feasible in developing regions. ${ }^{14}$ In such circumstances, observed incidence and prevalence could become highly dependent on factors other than the true occurrence of disease. For example, prevalence based on self-reported symptoms (chronic cough, sputum, and so on) may overestimate true COPD prevalence due to misclassification of other respiratory diseases. ${ }^{15}$ Furthermore, there is a considerable variation among studies in terms of case definition, study design, sample size, and data analysis, which makes comparisons and evaluation of the results among studies challenging. ${ }^{7}$

In this systematic review, we synthesized the available evidence among population-based epidemiologic studies and calculated the global prevalence of COPD in men and women. Additionally, summary estimates per geography, age, and across calendar time were provided, aiming to unravel potential differences in COPD prevalence between men and women. Finally, we applied a meta-regression approach to account for potential sources of heterogeneity.

\section{Materials and methods} Literature search

A comprehensive literature search that combined keyword terms and subject headings for the population of interest (eg, "COPD”) AND epidemiology (eg, "prevalence") was performed on August 19, 2015 across Medline and Embase for studies published from January 1, 2005 to August 19, 2015. The full search strategy and terms are available in the "Methods" section of the Supplementary materials. Screening was performed against predefined patients, interventions, comparators, and outcomes (PICO) selection criteria (Table S1) to identify population-based studies reporting the gender prevalence of COPD using the Digital Outcomes Conversion (DOC) Library System (Doctor Evidence, LLC, Santa Monica, CA, USA), a software platform featuring advanced term recognition within titles or abstracts, keyword search and ranking functionality, as well as management of reasons rejected for all references at all stages. Screening was performed by a single reviewer with subsequent quality control by an independent reviewer. Additional quality control was performed by an independent methodologist validating all included abstracts and a random sample of excluded abstracts using the Library Management System. Systematic reviews or meta-analyses of studies meeting the selection criteria were hand-checked and individual studies were included for extraction if they met the selection criteria. The references of individual studies were also back-checked for relevant studies.

\section{Data extraction}

A randomly selected sample consisting of $\sim 10 \%$ articles was extracted first in order to harmonize, refine, and calibrate the data extraction process. Data points and meta-data (variables that characterize numerical data points) were manually input into a predefined Microsoft Excel form by a single reviewer. A rigorous quality control process is described in detail in the "Methods" section of the Supplementary materials.

Important study methods and details, patient characteristics, and outcomes were extracted from all studies. The following outcome-level covariates were collected: the diagnostic method (spirometry, patient-reported, self-reported, unclear, or mixed), forced expiratory volume in 1 second $\left(\mathrm{FEV}_{1}\right) /($ vital capacity [VC] or forced vital capacity [FVC]) (eg, $<70 \%$ vs $<$ lower limit of normal [LLN]), $\mathrm{FEV}_{1}$ percent predicted $[\mathrm{PP}]$ to denote severity $(>80$ mild, $50-80$ moderate, $30-50$ severe, $<30$ very severe), whether spirometry was measured before or after bronchodilation (pre, post, or unclear), whether the data were adjusted or unadjusted (ie, crude) and what adjustments were performed, the source population (ie, unique population identifier), the country, geographic subregions, urbanity (urban, rural, mixed, or unclear), the intended scope of sampling (global, national, subnational, community, mixed, or unclear), the calendar time, and whether the outcome reflected point or period prevalence (follow-up time period was extracted if the outcome reflected period prevalence).

\section{Data synthesis and meta-regression}

To conduct the meta-analysis, each individual study prevalence (as provided or calculated by the available data) was transformed using a double arcsine approach. ${ }^{16}$ The transformed values were synthesized using a Bayesian random-effects approach ${ }^{17}$ and then the overall estimate was back-transformed to get the summary prevalence estimates. Additional details on the choice of priors for the Bayesian 
meta-analysis are provided in the "Methods" section of the Supplementary materials.

We performed analyses using 1) the most precise estimate of each study (ie, adjusted estimates wherever available) and 2) the crude estimates only. Whenever a prevalence estimate was not provided, we calculated it from the available data. Finally, we reported summary gender-specific estimates and their credible intervals (CrIs) separately for the conducted analyses.

To assess heterogeneity, we calculated the between-study variance using $\tau^{2}$. Then, we transformed $\tau^{2} \tau$ o $I^{2}$ (the ratio of true heterogeneity to total observed variation) using the formula $\tau^{2}=\tau^{2} /\left(\tau^{2}+\sigma^{2}\right) . I^{2}$ which ranges from 0 to $100 \%$ denotes the percentage of the variability in effect estimates that is due to heterogeneity rather than sampling error (chance). ${ }^{18,19}$ Values $>75 \%$ denote considerable heterogeneity.

We accounted for the inter-study variability in prevalence using a meta-regression approach as described in the "Methods" section of the Supplementary materials. The covariates that were considered in the meta-regression model were: age, diagnostic method including all definitions (patient-reported, physician diagnosis, mixed, $\mathrm{FEV}_{1} / \mathrm{FVC}<70 \%, \mathrm{FEV}_{1} /$ FVC $<70 \%$ and $\mathrm{FEV}_{1}<80 \mathrm{PP}, \mathrm{FEV}_{1} / \mathrm{FVC}<\mathrm{LLN}$ ), pre- and post-bronchodilator measurements, region, study setting (urban, rural, mixed), and calendar year. Adjusted estimates were controlled in the meta-regression by introducing an additional factor that denoted if the estimate that was used in the meta-regression was adjusted or not.

\section{Subgroup analysis}

In order to address potential confounding and reduce heterogeneity, we performed several subgroup analyses by age groups, World Health Organization (WHO) subregions (Box S1), income category (Box S2), study setting (urban, rural, mixed), disease severity, and calendar year. Specific definitions of the subgroups are presented in the "Methods" section of the Supplementary materials.

\section{Sensitivity analysis}

We performed sensitivity analyses for various subregions, income groups, and study setting, focusing on studies including participants aged $>40$, participants diagnosed using a spirometrybased definition, and studies including participants $>40$ who were also diagnosed with spirometry-based definitions.

\section{Results}

The systematic search returned 8,317 article titles studies. Five hundred and twenty-two studies were selected for full-text screening, of which 194 were included for extraction and 156 articles were included in the meta-analysis. Of the 38 articles excluded from the meta-analysis, 28 pertained to smaller, overlapping populations and 10 studies did not report the data such that they could be used in the meta-analysis. A flowchart of the selected studies is presented in Figure S1.

Finally, 156 studies (155 for females) were available for the meta-analysis, representing 1,650,854 and 1,655,579 total number of COPD cases for men and women, respectively. Crude estimates were provided or could be calculated in 109 studies, while adjusted estimates were available in 47 studies. Studies were mainly adjusted on age $(n=18)$ alone, or various factors, such as smoking, response rate in study participation, and region $(\mathrm{n}=15)$. Moreover, 14 studies weighted prevalence estimates based on another source population. Summary tables of the eligible studies are presented in Tables $\mathrm{S} 2$ and $\underline{\mathrm{S} 3}$.

Eligible studies were conducted across 12 regions as defined by WHO (Box S1). European and American regions had the highest number of studies with 66 and 41 studies, respectively. Six studies were conducted in multiple countries; they included the BOLD study, the PLATINO study in Latin America, the BREATH study, and the WHO LARES study. Across all studies, 58 countries were represented, with the USA contributing the largest number of studies $(n=31)$. The mean age of participants across studies was 48.8 years and a range of 12-99 years. The eligible studies mainly used Global initiative for chronic Obstructive Lung Disease (GOLD) guidelines $(n=64)$ for defining COPD cases, whereas American Thoracic Society (ATS), ATS/European Respiratory Society, and the British Thoracic Society guidelines were also reported. Spirometry was the most commonly used method for diagnosing COPD $(n=75)$, followed by self-report $(n=52)$, physician diagnosis $(n=24)$, or mixed definitions $(n=23)$.

\section{Overall analysis}

Meta-analysis of all 156 eligible studies yielded a summary prevalence of $9.23 \%$ (95\% CrI: $8.16 \%-10.36 \%$ ) and $6.16 \%$ (95\% CrI: 5.41\%-6.95\%) for men and women, respectively (Table 1). When the analysis was restricted to participants 40 years or older, the summary prevalence increased to $11.55 \%$ and $7.47 \%$, respectively. Interestingly, in studies using spirometry to diagnose COPD, the summary prevalence was $13.09 \%$ and $7.59 \%$, respectively $(n=75)$, and was even higher when the analysis was focused to participants aged 40 or older $(\mathrm{n}=51$; Table 1). Self-report and physician-based diagnoses provided similar lower prevalence for men and women, suggesting that COPD is considerably underreported (Table 1). 
Table I Summary estimates of prevalence for men and women for different definitions of COPD

\begin{tabular}{llll}
\hline Definition & $\begin{array}{l}\text { No of studies } \\
\text { (men/women) }\end{array}$ & \multicolumn{2}{l}{ Prevalence \% (95\% CrI) } \\
\cline { 3 - 4 } & $156 / 155$ & Men & Women \\
\hline Overall & $97 / 97$ & $9.23(8.16-10.36)$ & $6.16(5.41-6.95)$ \\
Age $\geq 40$ years & $75 / 75$ & $11.55(10.30-12.86)$ & $7.47(6.60-8.36)$ \\
Spirometry-based definition & $51 / 51$ & $13.09(11.58-14.65)$ & $7.59(6.49-8.80)$ \\
Age $\geq 40$ years and & & $14.71(12.74-16.71)$ & $8.70(7.29-10.26)$ \\
spirometry-based definition & $52 / 52$ & & $4.89(4.04-5.84)$ \\
Patient reported & $24 / 24$ & $4.92(4.17-5.77)$ & $3.98(2.18-6.20)$ \\
Physician diagnosis & $23 / 23$ & $4.96(2.93-7.52)$ & $6.13(4.13-8.48)$ \\
Mixed & & $10.64(7.31-14.47)$ & \\
\hline
\end{tabular}

Abbreviation: $\mathrm{Crl}$, credible interval.

Clinical and methodological diversity between studies led to statistical heterogeneity. In our study, as expected, we observed very large heterogeneity. Briefly, in all performed analyses, the observed heterogeneity as measured by $I^{2}$ statistic was statistically significant and in all analyses, it was $>95 \%$. In order to address this large between-studies heterogeneity, analyses examining subgroups based on geographic region, income, urbanity, age, severity, and calendar time were conducted. Heterogeneity was further assessed using a meta-regression approach.

\section{Stratified analysis by regions and urbanity}

The analysis by WHO subregions (Box S1) on the overall population is summarized in Table 2. For males, the highest prevalence was observed in South-East Asian Region D (SEAR D; 11.34\%; CrI: 8.32\%-14.68\%) followed by Western Pacific
Region A (WPR A; 10.14\%; CrI: 5.09\%-16.63\%) and Western Pacific Region B (WPR B; 9.20\%; CrI: 5.89\%-13.20\%). For females, the highest summary prevalence was observed in Region of the Americas A (AMR A; 7.30\%; CrI: 5.89\%$8.84 \%)$ followed by WPR A (6.16\%; CrI: $2.93 \%-10.65 \%)$ and European Region A (EUR A; 6.10\%; CrI: 5.04\%-7.25\%).

When examining geography using World Bank's income categories (Box S2), summary prevalence was highest in upper-middle income countries for males $(9.00 \%)$ and in high-income countries for females $(6.32 \%$; Table 2).

Regarding urbanity, urban dwellers had higher COPD prevalence compared to rural and mixed populations, with a summary prevalence of $13.03 \%$ (95\% CrI: $11.28 \%-14.92 \%$ ) and $8.34 \%$ (95\% CrI: $7.06 \%-9.75 \%)$ for men and women, respectively.

Table 2 Summary estimates of prevalence for men and women for various subregions, income groups, and study setting

\begin{tabular}{|c|c|c|c|}
\hline \multirow[t]{2}{*}{ Population } & \multirow{2}{*}{$\begin{array}{l}\text { No of studies } \\
\text { (men/women) }\end{array}$} & \multicolumn{2}{|c|}{ Prevalence \% (95\% Crl) } \\
\hline & & Men & Women \\
\hline Overall & $156 / 155$ & $9.23(8.16-10.36)$ & $6.16(5.4 I-6.95)$ \\
\hline \multicolumn{4}{|c|}{ Geographic regions } \\
\hline AMR A & $39 / 38$ & 8.07 (6.39-9.94) & $7.30(5.89-8.84)$ \\
\hline AMR B & $7 / 7$ & $6.44(4.34-8.98)$ & $2.49(1.22-4.20)$ \\
\hline EUR A & $64 / 64$ & $9.13(7.58-10.81)$ & $6.10(5.04-7.25)$ \\
\hline EUR B & $5 / 5$ & $7.86(3.15-11.63)$ & $4.39(1.56-8.5 I)$ \\
\hline SEAR D & $14 / 14$ & | I.34 (8.32-| |4.68) & $5.02(3.8 \mathrm{I}-6.42)$ \\
\hline WPR A & $7 / 7$ & $10.14(5.09-16.63)$ & $6.16(2.93-10.65)$ \\
\hline WPR B & $15 / 15$ & $9.20(5.89-13.20)$ & $4.86(2.79-7.48)$ \\
\hline \multicolumn{4}{|c|}{ World Bank income groups } \\
\hline Lower-middle & $10 / 10$ & $7.49(4.98-10.51)$ & $2.98(1.65-4.63)$ \\
\hline Upper-middle & $30 / 30$ & $9.00(7.14-11.01)$ & 4.61 (3.37-5.98) \\
\hline High & $115 / 114$ & $8.94(7.8 I-10.15)$ & $6.32(5.52-7.22)$ \\
\hline \multicolumn{4}{|l|}{ Study setting } \\
\hline Mixed/unclear & $117 / 116$ & $8.35(7.12-9.58)$ & $5.68(4.85-6.58)$ \\
\hline Rural & $17 / 18$ & $10.69(6.89-15.24)$ & $5.96(3.81-8.54)$ \\
\hline Urban & $44 / 45$ & |3.03 (| | $1.28-\mid 4.92)$ & $8.34(7.06-9.75)$ \\
\hline
\end{tabular}

Note: Numbers in bold represent the highest prevalence in each stratification category for men and women.

Abbreviations: AMR A, Region of the Americas A; AMR B, Region of the Americas B; EUR A, European Region A; EUR B, European Region B; SEAR D, South-East Asian Region D; WPR A, Western Pacific Region A; WPR B, Western Pacific Region B; Crl, credible interval. 
Table 3 Prevalence summary estimates for different age groups

\begin{tabular}{llll}
\hline $\begin{array}{l}\text { Age } \\
\text { subgroups }\end{array}$ & $\begin{array}{l}\text { No of studies } \\
\text { (men/women) }\end{array}$ & Prevalence \% (95\% CrI) & Women \\
\hline $15-39$ & $22 / 22$ & Men & $3.35(2.22-4.70)$ \\
$40-69$ & $51 / 51$ & $3.57(2.27-5.15)$ & $6.30(5.47-7.20)$ \\
$70+$ & $30 / 29$ & $10.08(8.77-11.46)$ & $\mathbf{1 5 . 9 0 ( 1 2 . 9 7 - 1 9 . 1 8 )}$ \\
Broad & $91 / 90$ & $\mathbf{2 7 . 2 4 ( 2 2 . 4 3 - 3 2 . 5 2 )}$ & $5.73(4.90-6.62)$ \\
\hline
\end{tabular}

Note: Numbers in bold represent the highest prevalence for men and women. Abbreviation: $\mathrm{Crl}$, credible interval.

\section{Stratified analysis by age}

We performed several analyses by age groups as minimum enrollment age and mean age have a direct influence on prevalence estimates (Table 3 ). The analyses limited to participants $\geq 40$ years old ( $\mathrm{n}=97$ studies) yielded a prevalence of $11.55 \%(10.30 \%-12.86 \%)$ and $7.47 \%(6.60 \%-8.36 \%)$ for men and women, respectively. Summary prevalence was lowest in the youngest age group - 3.57\% (95\% CrI: $2.27 \%-5.15 \%$ ) and $3.35 \%$ (95\% CrI: $2.22 \%-4.70 \%$ ) in men and women aged 15-39 ( $\mathrm{n}=22)$ - and highest in participants $\geq 70$ years old $-27.24 \%$ (95\% CrI: $22.43 \%-32.52 \%$ ) and $15.90 \%$ (95\% CrI: $12.97 \%-19.18 \%)$ in men and women, respectively $(n=30)$. Analyses in various age groups are summarized in Table 3. Several other analyses by different age group definitions are reported in Table S4.

\section{Stratified analysis by spirometry-based diagnostic criteria}

Several different spirometry based definitions were recorded across studies: $\mathrm{FEV}_{1} / \mathrm{FVC}<70 \%(\mathrm{n}=59), \mathrm{FEV}_{1} / \mathrm{FVC}<70 \%$ and $\mathrm{FEV}_{1}<80 \mathrm{PP}(\mathrm{n}=12)$, and FEV/FVC $<$ LLN (n=24). The overall prevalence for men and women is summarized in Table 4. It is notable that the closest prevalence estimates between genders were seen when the LLN criteria were applied.

\section{Stratified analysis by severity}

The summary prevalence of COPD in various severity stages is summarized in Figure 1 and Table S5. Low prevalence estimates were observed for severe $\left(30 \mathrm{PP}<\mathrm{FEV}_{1}<50 \mathrm{PP}\right)$ and very severe $\left(\mathrm{FEV}_{1}<30 \mathrm{PP}\right)$ categories; however, this could be attributed to the fact that the population is getting older and they die from other causes or COPD as the disease progresses.

\section{Stratified analysis by calendar time}

The subgroup analysis by calendar time did not show any trend over the years (Figure 2; Table S6); however, studies published prior to 2005 were not included. The overall prevalence in the latest studied calendar time (2010-2014) for men and women was $8.00 \%$ and $5.03 \%$, respectively. These studies were conducted mainly in AMR A ( $\mathrm{n}=7$ studies) and in EUR A ( $\mathrm{n}=4)$.

\section{Sensitivity analysis}

Sensitivity analyses confirmed the observed summary estimates and trends presented in the analyses before. Consistently, for females, the highest summary prevalence (and the smallest difference compared to males) was observed in Americas A. All summary estimates for various subregions, income groups, and study setting for population aged over 40 , diagnosed using spirometry-based definitions or combination of both criteria, are presented in Tables S7- $\underline{\mathrm{S} 9}$.

\section{Analysis using crude estimates}

The meta-analysis using crude estimates only did not alter the results. Summary estimates were similar and are summarized in Table S10. Briefly, the overall prevalence was

Table 4 Summary estimates of prevalence for men and women based on different diagnostic criteria

\begin{tabular}{|c|c|c|c|}
\hline \multirow{2}{*}{$\begin{array}{l}\text { Spirometry-based diagnostic } \\
\text { criteria }\end{array}$} & \multirow{2}{*}{$\begin{array}{l}\text { No of studies } \\
\text { (men/women) }\end{array}$} & \multicolumn{2}{|c|}{ Prevalence \% (95\% Crl) } \\
\hline & & Men & Women \\
\hline $\mathrm{FEV}_{1} / \mathrm{FVC}<70 \%$ & $59 / 59$ & | 3.47 (12.00-| 4.97) & $7.75(6.56-8.97)$ \\
\hline $\mathrm{FEV}_{1} / \mathrm{FVC}<70 \%$ and $\mathrm{FEV},<80 \mathrm{PP}$ & $12 / 12$ & $9.74(8.98-10.62)$ & $5.96(4.59-7.49)$ \\
\hline $\mathrm{FEV}_{1} / \mathrm{FVC}<\mathrm{LLN}$ & $24 / 24$ & $9.68(7.52-12.22)$ & $7.08(5.29-9.13)$ \\
\hline
\end{tabular}

Note: Numbers in bold represent the highest prevalence category for men and women.

Abbreviations: $\mathrm{Crl}$, credible interval; $\mathrm{FEV}_{1}$, forced expiratory volume in I second; FVC, forced vital capacity; LLN, lower limit of normal; PP, percent predicted. 


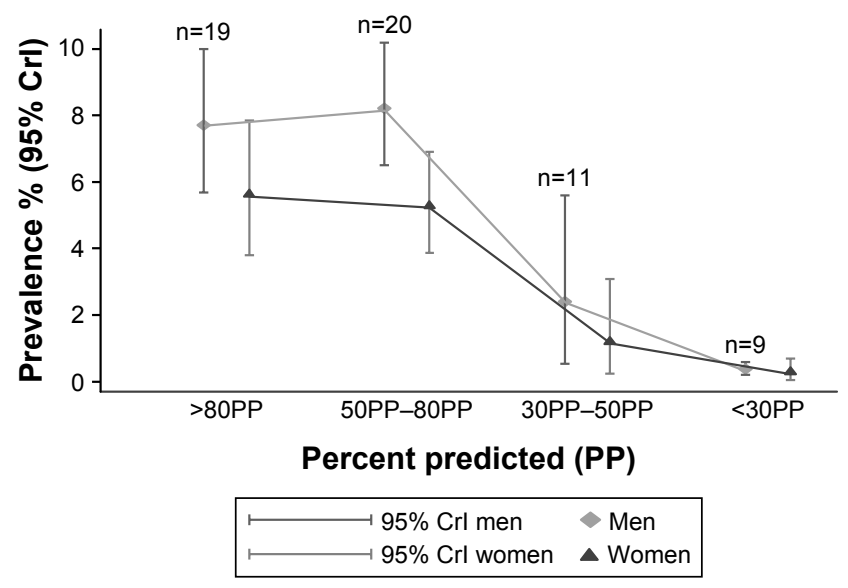

Figure I Summary estimates of prevalence for men and women by severity.

9.24\% (95\% CrI: $8.17 \%-10.36 \%)$ and $6.15 \%$ (95\% CrI: $5.41 \%-6.94 \%)$ for males and females, respectively, for all eligible articles. When the analysis was limited to populations over 40 years, the summary prevalence was $11.57 \%$ and $7.44 \%$, respectively.

\section{Meta-regression}

In order to assess possible sources of heterogeneity, we performed a meta-regression of the prevalence rates, including the subregions, the study setting (urban, rural, mixed), age, the diagnostic method including all definitions (patientreported, physician diagnosis, mixed, $\mathrm{FEV}_{1} / \mathrm{FVC}<70 \%$, $\mathrm{FEV}_{1} / \mathrm{FVC}<70 \%$ and $\mathrm{FEV}_{1}<80 \mathrm{PP}, \mathrm{FEV}_{1} / \mathrm{FVC}<\mathrm{LLN}$ ), calendar time, pre- or post-bronchodilator testing, and if crude or adjustment estimates were used as covariates. Using a backward elimination procedure with the aforementioned factors, our meta-regression analysis revealed a significant effect of studies including participants $>40$ years old and bronchodilator testing on estimated COPD prevalence rates in men. In women, only bronchodilator testing remained

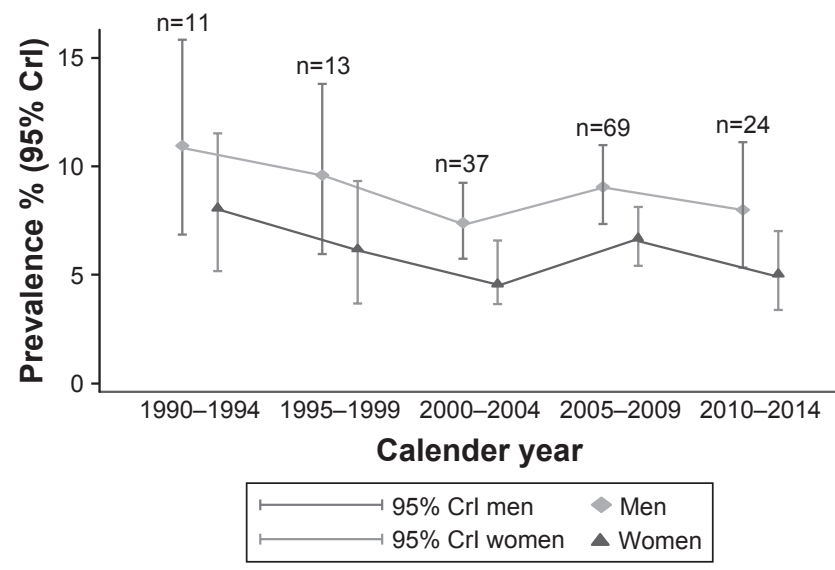

Figure 2 Summary estimates of prevalence for men and women by calendar time. significant in the meta-regression (Table 5). The other factors were not significant and they were dropped from the final model.

\section{Discussion}

This review systematically collected the available evidence and estimated a gender-specific summary prevalence for COPD, globally and across several regions of the world. To our knowledge, this is the largest systematic review and meta-analysis conducted to date for the estimation and assessment of potential gender differences of COPD prevalence. The global summary prevalence derived from $>150$ studies was $9.2 \%$ for men and $6.2 \%$ for women (so, a $1-0.67$ ratio), both of which are comparable to estimates from previous systematic reviews. ${ }^{3,20}$ Even though the prevalence of COPD was higher in men compared to women across various regions of the world and settings, these differences were often smaller than had been previously thought, and in developed and high-income countries, the differences were not statistically significant.

For men, the highest prevalence was observed in the SEAR D (11.3\%), whereas both WPR A and WPR B had estimates around $10 \%$. For women, the highest prevalence was observed in the AMR A; (which included studies from the USA and Canada only) with a summary prevalence of $7.3 \%$. This estimate was followed by the WPR A and EUR A (which consisted of mainly European Union countries). Of interest, the smallest differences in the summary prevalence estimates between men and women were observed in the AMR A and EUR A. Specifically, in the AMR A (studies from the USA and Canada), the prevalence was $8.07 \%$ vs $7.30 \%$ in men and women, respectively, whereas in the EUR A (mostly European Union countries), the prevalence was $9.13 \%$ vs $6.10 \%$. In both cases, overlapping $95 \%$ credible intervals were observed, denoting a nonsignificant difference. This may reflect a shared genetic background and exposure to similar risk factors, as well as the design of high-quality studies using standardized research protocols. Similarly, nonsignificant differences were observed when we used World Bank's income categories; in high-income countries, the summary prevalence was $8.94 \%$ vs $6.32 \%$ with overlapping credible intervals for men and women, respectively. Similar trends were observed in the sensitivity analysis.

We also found that prevalence was higher in urbanized regions. In our study, the prevalence in urban areas was $13.03 \%$ and $8.34 \%$ for men and women, respectively, compared to $10.69 \%$ and $5.96 \%$ in rural areas. The increasing rate of urbanization in many parts of the world, including 
Table 5 Summary of meta-regression analysis in men and women

\begin{tabular}{|c|c|c|c|c|c|c|}
\hline Population & Coefficient & SD & MCSE & Median & $\begin{array}{l}95 \% \text { Crl } \\
\text { lower }\end{array}$ & $\begin{array}{l}95 \% \mathrm{Crl} \\
\text { upper }\end{array}$ \\
\hline \multicolumn{7}{|l|}{ Men } \\
\hline Age $\geq 40$ years & 0.085 & 0.033 & 0.001 & 0.085 & 0.022 & 0.155 \\
\hline Post-bronchodilator & 0.265 & 0.042 & 0.003 & 0.265 & 0.186 & 0.350 \\
\hline Pre-bronchodilator & 0.323 & 0.048 & 0.003 & 0.324 & 0.228 & 0.416 \\
\hline Unclear & 0.229 & 0.046 & 0.002 & 0.229 & 0.135 & 0.318 \\
\hline \multicolumn{7}{|l|}{ Women } \\
\hline Age $\geq 40$ years & 0.047 & 0.031 & 0.002 & 0.049 & -0.022 & 0.102 \\
\hline Post-bronchodilator & 0.103 & 0.039 & 0.002 & 0.100 & 0.027 & 0.179 \\
\hline Pre-bronchodilator & 0.191 & 0.047 & 0.003 & 0.189 & 0.103 & 0.286 \\
\hline Unclear & 0.105 & 0.045 & 0.002 & 0.105 & 0.016 & 0.189 \\
\hline
\end{tabular}

Abbreviations: $\mathrm{Crl}$, credible interval; MCSE, Monte Carlo standard error.

China, may have contributed to an increased prevalence of COPD. Of course, differences observed in regional prevalence may reflect true differences; however, they may also be associated with heterogeneity introduced from various sources such as the population structure, age range, definition of the outcomes, types of diagnosis, and increased rates of smoking in developed countries. Moreover, there are empirical studies demonstrating that despite the large burden of COPD in WPR B, SEAR B, and SEAR D, only a few epidemiologic surveys of high quality on COPD exist in these regions. ${ }^{21}$

\section{Limitations}

This review has some limitations. The analyses were based on cases with different definitions that vary from self-reported to spirometry-based outcomes, a fact that increases the observed heterogeneity and may affect the summary prevalence estimates in our study. Even among spirometry-based studies, definitions varied due, in part, to changes in diagnostic guidelines over time or based on the FEV/FVC $<70 \%$ in accordance with the most recent GOLD guidelines. ${ }^{22}$ However, some have argued that this criterion may overdiagnose COPD in the elderly and underdiagnose the prevalence in younger populations. ${ }^{23,24} \mathrm{LLN}$ has, therefore, been proposed as an alternative, but this criterion was less frequently used in the list of eligible studies of this review. Furthermore, even in studies where $\mathrm{FEV} / \mathrm{FVC}<70 \%$ was used as definition, measurements were generally based on pre-bronchodilator values rather than post-bronchodilator values as recommended by the GOLD criteria. In fact, whether the study used a pre- or post-bronchodilator measurement was significant in metaregression, indicating that pre-bronchodilator measurements could be an important source of heterogeneity in the study and it should be taken into consideration when inferences are drawn.
Our review attempted to collect factors that may confound the estimates of COPD between studies. These factors were explored in both subgroup analysis and meta-regression. It is, however, possible that additional confounding factors existed that were not accounted for. In addition, these factors could not be collected for all studies. Even with this rigorous assessment of confounding, heterogeneity remained high and no factors explained a significant proportion of the heterogeneity observed. This finding highlights the challenges of systematically reviewing the global prevalence of disease, particularly for a condition such as COPD where differences in case definition, study design, and baseline population characteristics make the meta-analysis challenging.

Finally, even though this is the largest systematic study of gender prevalence in the field of COPD to date, we have limited our search to include studies published from 2005 onward. Therefore, assessment of temporal trends in the prevalence of COPD is difficult and should be interpreted with caution.

Our findings suggest a closing of the gap in COPD prevalence worldwide and regionally between men and women, especially in developed, high-income countries and in urbanized settings. This observation is likely due to the fact that smoking rates in women have increased dramatically ${ }^{25}$ in some regions of the world, and it is likely that similar smoking rates exist in those regions. Additionally, this finding may reflect the fact that women are more susceptible to the effects of smoking and COPD development. ${ }^{11,12}$ Specifically, women often have similar levels of impaired lung function despite having smoked much less, suggesting an accelerated decline in lung function in women who smoke. ${ }^{26,27}$ Alternative explanations such as air pollution and its differential effect on women as well as hormonal influences on disease development should also be considered.

In conclusion, this large meta-analysis helps to highlight the increasing prevalence of COPD in the female population. 
This is an important factor to take into consideration when considering alternatives to diagnosis in women.

Recent literature suggests increasing burden of COPD in women, but no comprehensive review has been performed. This work is the largest ever systematic review and metaanalysis of global prevalence of COPD and the first large gender-specific review. These results will increase awareness of COPD as a critical woman's health issue.

\section{Data sharing statement}

This article has an online data supplement, which is accessible from this issue's table of content online at www. atsjournals.org.

\section{Acknowledgments}

This meta-analysis was performed by Doctor Evidence and funded by Novartis Pharma AG. Arielle Levy, of Doctor Evidence, provided data quality control and Angelica Stamegna provided editorial assistance.

\section{Disclosure}

The authors report no conflicts of interest in this work.

\section{References}

1. Murray CJ, Vos T, Lozano R, et al. Disability-adjusted life years (DALYs) for 291 diseases and injuries in 21 regions, 1990-2010: a systematic analysis for the Global Burden of Disease Study 2010. Lancet. 2012;380:2197-2223.

2. Lozano R, Naghavi M, Foreman K, et al. Global and regional mortality from 235 causes of death for 20 age groups in 1990 and 2010: a systematic analysis for the Global Burden of Disease Study 2010. Lancet. 2012;380:2095-2128.

3. Adeloye D, Chua S, Lee C, et al. Global and regional estimates of COPD prevalence: systematic review and meta-analysis. J Glob Health. 2015;5:020415.

4. Burney PG, Patel J, Newson R, Minelli C, Naghavi M. Global and regional trends in COPD mortality, 1990-2010. Eur Respir J. 2015;45:1239-1247.

5. Han MK, Postma D, Mannino DM, et al. Gender and chronic obstructive pulmonary disease: why it matters. Am J Respir Crit Care Med. 2007;176:1179-1184.

6. Vos T, Flaxman AD, Naghavi M, et al. Years lived with disability (YLDs) for 1160 sequelae of 289 diseases and injuries 1990-2010: a systematic analysis for the Global Burden of Disease Study 2010. Lancet. 2012;380:2163-2196.

7. Lopez AD, Shibuya K, Rao C, et al. Chronic obstructive pulmonary disease: current burden and future projections. Eur Respir J. 2006;27: 397-412.

8. Lamprecht B, McBurnie MA, Vollmer WM, et al. COPD in never smokers: results from the population-based burden of obstructive lung disease study. Chest. 2011;139:752-763.
9. Mannino DM, Buist AS. Global burden of COPD: risk factors, prevalence, and future trends. Lancet. 2007;370:765-773.

10. McCarthy B, Casey D, Devane D, Murphy K, Murphy E, Lacasse Y. Pulmonary rehabilitation for chronic obstructive pulmonary disease. Cochrane Database Syst Rev. 2015;(2):CD003793.

11. Aryal S, Diaz-Guzman E, Mannino DM. Influence of sex on chronic obstructive pulmonary disease risk and treatment outcomes. Int J Chron Obstruct Pulmon Dis. 2014;9:1145-1154.

12. Sorheim IC, Johannessen A, Gulsvik A, Bakke PS, Silverman EK, DeMeo DL. Gender differences in COPD: are women more susceptible to smoking effects than men? Thorax. 2010;65:480-485.

13. Buist AS, Vollmer WM, Sullivan SD, et al. The Burden of Obstructive Lung Disease Initiative (BOLD): rationale and design. COPD. 2005; 2:277-283.

14. Barnes PJ. Chronic obstructive pulmonary disease: a growing but neglected global epidemic. PLoS Med. 2007;4:e112.

15. Kart L, Akkoyunlu ME, Bayram M, et al. COPD: an underdiagnosed disease at hospital environment. Wien Klin Wochenschr. 2014;126: 73-78.

16. Barendregt JJ, Doi SA, Lee YY, Norman RE, Vos T. Meta-analysis of prevalence. J Epidemiol Community Health. 2013;67:974-978.

17. Smith TC, Spiegelhalter DJ, Thomas A. Bayesian approaches to random-effects meta-analysis: a comparative study. Stat Med. 1995;14: 2685-2699.

18. Higgins JP, Thompson SG, Deeks JJ, Altman DG. Measuring inconsistency in meta-analyses. BMJ. 2003;327:557-560.

19. Ioannidis JP, Patsopoulos NA, Evangelou E. Uncertainty in heterogeneity estimates in meta-analyses. BMJ. 2007;335:914-916.

20. Halbert RJ, Natoli JL, Gano A, Badamgarav E, Buist AS, Mannino DM. Global burden of COPD: systematic review and meta-analysis. Eur Respir J. 2006;28:523-532.

21. Ko FW, Hui DS, Lai CK. Worldwide burden of COPD in high- and low-income countries. Part III. Asia-Pacific studies. Int J Tuberc Lung Dis. 2008;12:713-717.

22. Vestbo J, Hurd SS, Agusti AG, et al. Global strategy for the diagnosis, management, and prevention of chronic obstructive pulmonary disease: GOLD executive summary. Am J Respir Crit Care Med. 2013;187: 347-365.

23. Di Marco F, Tantucci C, Pellegrino G, Centanni S. Chronic obstructive pulmonary disease diagnosis: the simpler the better? Not always. Eur $J$ Intern Med. 2013;24:199-202.

24. Mohamed Hoesein FA, Zanen P, Lammers JW. Lower limit of normal or FEV1/FVC $<0.70$ in diagnosing COPD: an evidence-based review. Respir Med. 2011;105:907-915.

25. Ng M, Freeman MK, Fleming TD, Robinson M, et al. Smoking prevalence and cigarette consumption in 187 countries, 1980-2012. JAMA. 2014;311:183-192.

26. Silverman EK, Weiss ST, Drazen JM, et al. Gender-related differences in severe, early-onset chronic obstructive pulmonary disease. Am J Respir Crit Care Med. 2000;162:2152-2158.

27. Gan WQ, Man SF, Postma DS, Camp P, Sin DD. Female smokers beyond the perimenopausal period are at increased risk of chronic obstructive pulmonary disease: a systematic review and meta-analysis. Respir Res. 2006;7:52.
International Journal of COPD

\section{Publish your work in this journal}

The International Journal of COPD is an international, peer-reviewed journal of therapeutics and pharmacology focusing on concise rapid reporting of clinical studies and reviews in COPD. Special focus is given to the pathophysiological processes underlying the disease, intervention programs, patient focused education, and self management protocols.

\section{Dovepress}

This journal is indexed on PubMed Central, MedLine and CAS. The manuscript management system is completely online and includes a very quick and fair peer-review system, which is all easy to use. Visit $\mathrm{http}: / / \mathrm{www}$.dovepress.com/testimonials.php to read real quotes from published authors. 